\title{
Concentração Sérica Materna da Proteína C Reativa em Gestações Complicadas pela Pré-eclâmpsia
}

\author{
Maternal Serum Level of C-reactive Protein in Gestations Complicated by Preeclampsia \\ Antônio Carlos Vieira Cabral, Janaína de Freitas Lázaro, Zilma Nogueira Reis Vitral
}

\begin{abstract}
RESUMO
Objetivo: investigar a associação entre a concentração sérica da proteina $C$ reativa e a ocorrência de pré-eclâmpsia, bem como sua relação com a gravidade da doença.

Métodos: foram avaliadas, em estudo caso-controle transversal, 27 gestantes portadoras de pré-eclâmpsia e outras 27 sem nenhuma intercorrência clínica, no terceiro trimestre gestacional. As pacientes tiveram a dosagem sérica da proteina $C$ reativa realizada no periodo antenatal, além de exames clínico e laboratoriais para diagnóstico da doença. Foram investigadas a associação entre a concentração sérica da proteina $C$ reativa e a presença da pré-eclâmpsia e a correlação entre os valores desta proteina plasmática com os niveis da pressão arterial e excreção urinária de proteina. Empregou-se o teste de significância $\left(\chi^{2}\right) e$ análise de regressão pela técnica dos mínimos quadrados, considerando-se significância estatistica quando $p<0,05$.

Resultados: as gestantes portadoras de pré-eclâmpsia apresentaram niveis da pressão arterial

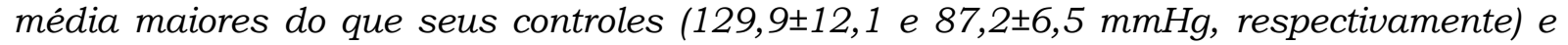
valores médios da proteina $C$ reativa significativamente superiores aos das normotensas $(18,9 \pm 4,9$ e 1,5 $\pm 0,8 \mathrm{mg} / \mathrm{L}$, respectivamente). Houve associação significativa entre a elevação da concentração de proteina $C$ reativa e a ocorrência da pré-eclâmpsia ( $p<0,0001$, "odds ratio": 20,1). Verificou-se também que a medida da pressão arterial média e a proteinúria apresentam correlação direta com a concentração da proteina $C$ reativa circulante no sangue materno ( $p=0,001$ e $p=0,018$, respectivamente).

Conclusão: a proteína $C$ reativa mostrou-se um marcador efetivo da ocorrência da préeclâmpsia e tem significativa correlação com a gravidade da doença. O uso deste exame para diagnóstico diferencial entre os diversos quadros hipertensivos da gestante e sua utilização como marcador de prognóstico da pré-eclâmpsia merecem novos estudos.
\end{abstract}

PALAVRAS-CHAVE: Hipertensão. Proteina $C$ reativa. Proteinúria.

\section{Introdução}

Há décadas, inúmeras teorias vêm sendo propostas para explicar a gênese da pré-eclâmpsia, mas até o momento nenhuma foi aceita de forma definitiva. Atualmente, dois fatores são considerados importantes no mecanismo fisiopatológico desta doença: o quadro da peroxidação lipídica e o da resposta inflamatória sistêmica exacerbada ${ }^{1,2}$.

Departamento de Ginecologia e Obstetrícia da UFMG Correspondência: Antônio Carlos V. Cabral

Rua dos Otoni, 909, sala 1804

30150-270 - Belo Horizonte -MG

Fone: (33) 273-0559

e-mail accabral@hc.ufmg.br
Sob vários aspectos, estas duas hipóteses se confundem em uma só, visto que podem ser entendidas como processos complementares, em que a primeira é capaz de desencadear a segunda situação clínica ${ }^{2}$. Parece que gestações com invasão trofoblástica deficiente tendem a desenvolver hipóxia tissular, levando a produção aumentada de peróxido lipídico no tecido placentário e elevação desta substância na circulação fetoplacentária $^{2}$. A capacidade dos peróxidos lipídicos de lesar células endoteliais é conhecida de longa data, sendo este o ponto de contato entre as duas teorias, já que a resposta inflamatória sistêmica, na maior parte das vezes, se inicia com a lesão endotelial ${ }^{1}$. Alguns trabalhos experimentais também 
demonstram que a pré-eclâmpsia constitui uma síndrome típica de exacerbação da resposta inflamatória sistêmica. A lesão endotelial com elevação das endotelinas, o aumento da agregação plaquetária e o depósito fibrinóide em diversos órgãos são componentes de um processo inflamatório sistêmico típico ${ }^{3,4}$. Observa-se na gravidez normal a elevação da atividade de granulócitos, monócitos e linfócitos, caracterizando a presença de atividade inflamatória ${ }^{3,4}$. No entanto, na préeclâmpsia a exacerbação desta atividade, caracterizada laboratorialmente pela elevação destes marcadores, constitui achado bastante sugestivo da participação do processo inflamatório na patogenia da doença ${ }^{1}$.

Algumas alterações já detectadas em mulheres portadoras de pré-eclâmpsia reforçam clínica e laboratorialmente este conceito estabelecido em animais de experimentação, como a ativação de neutrófilos e monócitos por meio de estudo com citometria de fluxo ${ }^{5}$. No entanto, o mecanismo que desencadeia a resposta inflamatória sistêmica exacerbada nas pacientes portadoras de pré-eclâmpsia não está bem esclarecido, embora se saiba que o quadro de deportação trofoblástica sistêmica seja capaz de ativar esta resposta ${ }^{5}$.

Também há indícios de que não só a préeclâmpsia, mas também alguns tipos de crescimento intra-uterino restrito, apresentem exacerbação do precesso inflamatório ${ }^{6}$, o que denota pontos em comum entre os mecanismos responsáveis pela gênese destas duas entidades.

A proteina $\mathrm{C}$ reativa (PCR), sintetizada no figado, está presente em baixas concentrações nas gestações normais. Em situações mórbidas agudas, tais como nas infecções, processos inflamatórios ou de destruição tecidual, ela se eleva rapidamente. Sua presença no sangue pode ser detectada a partir de reação de precipitação específica $^{7}$. Sua precocidade tem sido especialmente valorizada na sinalização do processo inflamatório em doenças cardiovasculares, pois se acredita que sua produção possa ser estimulada pela lesão do endotélio vascular ${ }^{7}$. Estudos comparativos mostram se tratar de marcador mais sensivel na detecção da resposta inflamatória endotelial, em relação a outros como o soro amilóide $A$, interleucina 6, Apo A, Apo B e homocisteína ${ }^{7}$. No entanto, sua inespecificidade faz com que fatores como o tabagismo e a obesidade, entre outros, possam produzir resultados falsos positivos.

As tentativas de se associar a pré-eclâmpsia às dosagens séricas da PCR são ainda incipientes. Rebelo et al. ${ }^{8}$ verificaram que a PCR está aumentada de duas a três vezes durante o terceiro trimestre em gestações complicadas pela préeclâmpsia, em relação às gestantes sem a referi- da doença, diferença que se exacerba no puerpério. Estudos também apontam um aumento na concentração da PCR, já no primeiro trimestre gestacional, em mulheres que desenvolverão préeclâmpsia ao final da gravidez, em relação aos controles que não apresentarão esta doença ${ }^{9}$. Assim, acredita-se que seja possivel que o quadro de resposta inflamatória crônica esteja presente antes das manifestações clínicas da pré-eclampsia, sendo a PCR e também outras citocinas inflamatórias, como o fator de necrose tumoral, potenciais marcadores precoces do processo patológico nestas situações.

Considerando que os conceitos da préeclâmpsia como um quadro de exacerbação da resposta inflamatória sistêmica são verdadeiros e que a PCR é importante marcador da resposta inflamatória, o presente estudo pretende verificar a existência de alteração no nível sérico da PCR em pacientes com pré-eclâmpsia e, ainda, buscar uma possivel correlação entre gravidade da doença e sua concentração plasmática na circulação materna.

\section{Pacientes e Métodos}

No período de março de 2000 a junho de 2001 foi realizado um estudo transversal caso-controle envolvendo 27 pacientes portadoras de pré-eclampsia e outras 27 gestantes sem nenhuma intercorrência clínica. No momento da inclusão no estudo, os grupos foram pareados quanto à paridade e idade gestacional, que variou de 25 a 40 semanas.

Para o diagnóstico de pré-eclâmpsia consideramos os critérios do "National High Blood Pressure Education Program Working Group on High Blood Pressure in Pregnancy"10. A verificação da pressão arterial foi realizada na posição sentada, considerando-se o $5^{\circ}$ som de Korotkoff. A proteinúria foi determinada em todas as gestantes, empregando-se fita medidora, em escala de 1 a 3 cruzes, em amostra única, após a verificação da pressão arterial.

As principais características clínicas e obstétricas das gestantes estudadas estão apresentadas na Tabela 1. Observou-se que as gestantes dos grupos hipertenso e normotenso apresentavam idade gestacional e paridade semelhantes, atendendo ao pareamento proposto.

A dosagem sérica da PCR foi realizada no período antenatal, ao serem selecionadas para o estudo. Para isto, foram retirados cerca de $5 \mathrm{~mL}$ de sangue venoso em tubo sem anticoagulante. A técnica para dosagem foi quantitativa, por nefelometria, empregando-se $0,5 \mathrm{~mL}$ de soro. $\mathrm{O}$ valor de referência para normalidade não poderia exceder a $6,0 \mathrm{mg} / \mathrm{L}$. 
Tabela 1 - Características das gestantes por grupo de estudo.

\begin{tabular}{lccr}
\hline & $\begin{array}{c}\text { Hipertensas } \\
(\mathbf{n}=\mathbf{2 7})\end{array}$ & $\begin{array}{c}\text { Normotensas } \\
(\mathbf{n}=\mathbf{2 7})\end{array}$ & $\mathbf{p}$ \\
\hline Idade gestacional (semanas) & $33,4 \pm 3,9$ & $34,1 \pm 3,8$ & 0,53 \\
Paridade & $2,0 \pm 1,4$ & $2,2 \pm 1,3$ & 0,70 \\
Pressão arterial média (mmHg) & $129,9 \pm 12,1$ & $87,2 \pm 6,5$ & $<0,00001(\mathrm{~s})$ \\
PCR (mg/L) (média \pm EP) & $18,9 \pm 4,9$ & $1,56 \pm 0,8$ & $0,002(\mathrm{~s})$ \\
\hline EP: erro padrão, PCR: proteína C reativa, s: significante & & &
\end{tabular}

Os casos foram então analisados sob dois aspectos. Estudou-se a associação entre a alteração da PCR (valores superiores a $6,0 \mathrm{mg} / \mathrm{L}$ ) e a ocorrência de pré-eclâmpsia. Também foi verificada a existência de correlação entre a concentração sérica da PCR e os níveis médios da pressão arterial (PAM) e entre esta mesma proteína circulante e a proteinúria.

Os valores da PAM, PCR, idade gestacional e paridade dos dois grupos foram comparados empregando-se o teste $t$ de médias. Para verificar a associação entre a ocorrência de pré-eclâmpsia e niveis anormais da PCR empregou-se teste do tipo $\chi^{2}$. A correlação entre PCR e PAM e entre PCR e excreção urinária de proteínas, avaliadas como variáveis contínuas, foi obtida por meio de análise de regressão, pela técnica dos quadrados mínimos. A análise dos dados foi executada empregando-se o programa Minitab Inc. ${ }^{\circledR}$, versão 11.12 , de 1996. O nivel de significância aceitável para os testes de hipótese foi $\mathrm{p}<0,05$.

O estudo foi aprovado pela Comissão de Ética do Hospital das Clínicas da UFMG e as gestantes forneceram consentimento de participação.

\section{Resultados}

As gestantes portadoras de pré-eclâmpsia apresentaram niveis da PAM, em média, maiores do que seus controles, como esperado $(129,9 \pm 12,1$ e $87,2 \pm 6,5 \mathrm{mmHg}$, respectivamente) e ainda valores médios da PCR significativamente superiores às normotensas, $(18,9 \pm 4,9$ e $1,5 \pm 0,8 \mathrm{mg} / \mathrm{L}$, respectivamente), conforme mostrado na Tabela 1.

Na Tabela 2 são apresentados os resultados da concentração sérica da PCR como valor normal e alterado, considerando-se o corte de $6,0 \mathrm{mg} / \mathrm{L}$, por grupo de estudo. O valor anormal do teste esteve associado ao diagnóstico da pré-eclâmpsia ( $p<0,0001$, "odds ratio": 20,1 ), sendo que entre as 27 gestantes com teste anormal, 21 apresentavam a doença.

Na Figura 1, a PCR foi plotada em função da PAM em $\mathrm{mmHg}$, sendo também expressa a equa- ção de regressão. Ficou evidente a existência de correlação positiva entre as duas variáveis.

Tabela 2 - Relação entre PCR alterada e ocorrência de pré-eclâmpsia.

\begin{tabular}{lccc}
\hline & $\begin{array}{c}\text { Hipertensas } \\
(\mathbf{n}=\mathbf{2 7})\end{array}$ & $\begin{array}{c}\text { Normotensas } \\
(\mathbf{n}=27)\end{array}$ & Total \\
\hline PCR alterado & 21 & 4 & 25 \\
PCR normal & 6 & 23 & 29 \\
Total & 27 & 27 & 54 \\
\hline$\chi^{2}: 21,53$, p<0,0001 (com correção de Fisher); "odds ratio": 20,1 (IC 4.2 a 108,54) \\
IC: intervalo de confiança; p: significância; PCR: proteina C reativa
\end{tabular}

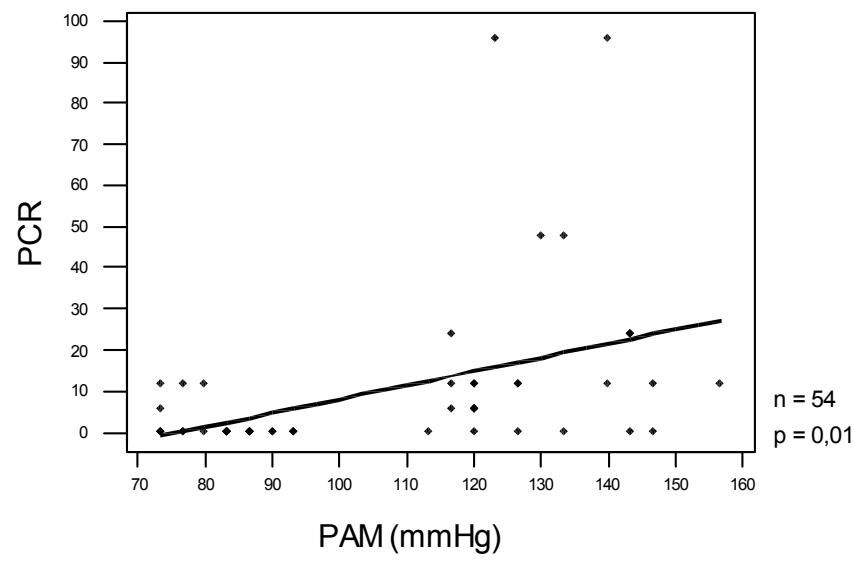

PCR $=-25,7+0,338$ PAM, (IC: 0,18 a 0,49), $p=0,001$.

A linha contínua representa a reta de regressão.

IC: intervalo de confiança; p: significância; PAM: pressão arterial média; PCR: proteína C reativa

Figura 1 - Correlação entre a pressão arterial média e a concentração plasmática da proteína $\mathrm{C}$ reativa.

A correlação entre a $\mathrm{PCR}$ e a proteinúria, ilustrada pela Figura 2 e expressa pela equação de regressão, também foi direta e significante.

\section{Discussão}

A relação da pré-eclampsia com a resposta inflamatória exacerbada já está razoavelmente definida $^{1,11}$. Não há dúvidas de que existe ativa- 
ção do processo inflamatório precocemente na fisiopatologia da doença. No entanto, o exato momento em que o processo se inicia permanece desconhecido ${ }^{12}$. Para Redman et al. ${ }^{1}$, provavelmente a invasão trofoblástica insuficiente que se observa nas gestações complicadas pela préeclampsia já seria decorrência da exacerbação inflamatória. Para Rebelo et al. ${ }^{8}$, que verificaram a ativação de vários marcadores da resposta inflamatória na pré-eclampsia, o processo decorre da lesão endotelial. Ambas as hipóteses são compatíveis com o achado de Luthy et al. ${ }^{9}$, que encontraram, desde o primeiro trimestre, a PCR elevada nas mulheres que ao final da gravidez apresentariam pré-eclâmpsia.

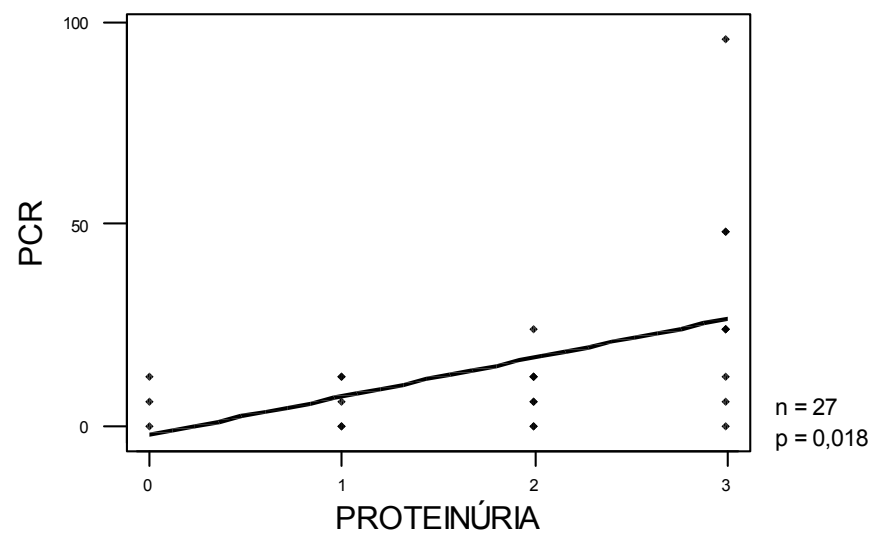

PCR $=-2.36+9.60$ Prot., (IC: 3,4 a 15,8), $p=0,018$

A linha contínua representa a reta de regressão.

IC: intervalo de confiança; $p$ : significância; Prot: proteinúria; PCR: proteína $C$ reativa

Figura 2 - Correlação entre proteinúria e concentração plasmática da proteína $\mathrm{C}$ reativa.

Não há dúvidas de que a PCR é um marcador de grande sensibilidade das inflamações sistêmicas, mas é também de baixa especificidade, podendo positivar-se em situações diversas ${ }^{7}$. Um aspecto importante que verificamos em nosso estudo foi a nítida correlação entre os níveis da PCR com o aumento da gravidade da pré-eclampsia, seja representado pela elevação da PAM ou pela acentuação da proteinúria, fazendo-nos acreditar que o agravamento da doença possa estar relacionado com a exacerbação da resposta inflamatória ou extensão da lesão endotelial. A diferença encontrada entre os níveis médios da PCR nas gestantes pré-eclâmpticas em relação aos controles (Tabela 1) e a presença de associação entre um valor anormal desta proteína e a presença da doença (Tabela 2) não deixa dúvida que este é um importante marcador da doença, mas não há uma boa definição de como ele deva ser utilizado, se para diagnóstico diferencial ou como prognóstico da doença. Este aspecto merecia avaliações futuras, bem como o acompanhamento destes niveis em usuárias bem selecionadas de aspirina, na determinação do prognóstico neste grupo específico. Estudos realizados em pacientes com vasculopatias sugerem uma ação importante do ácido acetilsalicílico na redução da resposta inflamatória endotelial ${ }^{13}$.

A PCR mostrou-se um efetivo e significativo marcador da presença da pré-eclâmpsia. Também, encontrou-se nítida correlação entre o aumento da PCR na circulação sanguínea e o agravamento dos niveis pressóricos e da excreção urinária de proteína nesta doença. Acredita-se que um valor acima de $6,0 \mathrm{mg} / \mathrm{L}$ da PCR plasmática possa ter valor diagnóstico e prognóstico do agravamento desta doença.

A explicação para os achados do presente estudo pode ser respaldada na teoria que apresenta a pré-eclâmpsia como doença inflamatória típica, de caráter sistêmico e de apresentação exacerbada, pois a lesão endotelial que caracteriza a préeclâmpsia é parte da resposta inflamatória e capaz de explicar a elevação da PCR.

Finalizando, é importante ressaltar a necessidade de investigações mais detalhadas que busquem relação mais consistente da pré-eclampsia com a resposta inflamatória sistêmica, o que tornará possivel a consolidação de novos marcadores de diagnóstico ou mesmo de predição, contribuindo sobremaneira para melhoria da propedêutica desta doença.

\section{ABSTRACT}

Purpose: to investigate the association between serum $C$ reactive protein concentration and preeclampsia occurrence, as well as its relation to the disease severity.

Patients and Methods: twenty-seven preeclamptic pregnant women and 27 pregnant women with no clinical intercurrences, in the third trimester of pregnancy, were evaluated in a transversal case-control study. Serum Creactive protein dosage, besides clinical examination and laboratory tests for the diagnosis of the disease, were performed in the antenatal period. The association between $C$-reactive protein and the presence of preeclampsia, and the correlation between plasma protein values and blood pressure values were investigated. The $\chi^{2}$ significance test and regression analysis through the square minimum technique were used, and the results were considered to be statistically significant when $p<0.05$.

Results: the preeclamptic pregnant women presented mean blood pressure levels higher than their controls $(129.9 \pm 12.1$ and $87.2 \pm 6.5 \mathrm{mmHg}$, respectively) and significantly higher $C$-reactive protein mean values than the normotensive women (18.9 \pm 4.9 and $1.56 \pm 0.8 \mathrm{mg} / \mathrm{L}$, respectively). There was a significant association between the C-reactive protein concentration increase and preeclampsia occurrence $(p<0.0001$, odds ratio: 20.1). It was also observed that the mean arterial pressure and proteinuria presented a direct correlation with the circulating $C$-reactive protein in 
maternal blood ( $p=0.001$ and $p<0.001$, respectively). Conclusion: $C$-reactive protein is an effective marker of preeclampsia occurrence and significantly correlates with the disease severity. The use of this test for the differential diagnosis of pregnant women in several hypertensive situations and its utilization as a marker of preeclampsia prognosis deserve further studies.

KEY-WORDS: Hypertension. C-reactive protein. Proteinuria.

\section{Referências}

1. Redman CW, Sacks GP, Sargent IL. Preeclampsia: an excessive maternal inflammatory response to pregnancy. Am J Obstet Gynecol 1999; 180:499-506

2. Kim YH, Ahn B, Song TB, Byun J. Lipide peroxidation and total peroxyl radical trapping ability of umbilical venous blood plasma in normal pregnancy and preeclampsia. Am J Obstet Gynecol 2001; 184:S75.

3. Faas MM, Bakker WW, Valkhof N, Baller JF, Schuiling GA. Plasma endothelin-1 and tumor necrosis factor-alpha concentrations in pregnant and cyclic rats after low dose endotoxin infusion. Am J Obstet Gynecol 1997; 177:429-30.

4. Fass MM, Schuiling GA, Linton EA, Sargent IL, Redman CW. Activation of peripheral leukocytes in rat pregnancy and experimental preeclampsia. Am J Obstet Gynecol 2000; 182:351-7.

5. Gervasi MT, Chaiworapongsa T, Pacora P, et al. Maternal systemic inflammation: a mechanism of disease in preeclampsia. Am J Obstet Gynecol 2001; 184:S11.
6. Sabatier F, Bretelle F, D'Ercole C, Boubli L, Sampol J, Dignat-George F. Neutrophil activation in preeclampsia and isolated intrauterine growth restriction. Am J Obstet Gynecol 2000; 183:1558-63.

7. Rocha MOC, Pedroso ERP, Fonseca JGM, Silva OA. A resposta inflamatória. In: Enio Pietra. Terapêutica Clínica. $1^{\mathrm{a}}$ ed. Rio de Janeiro: Guanabara-Koogan; 1998. p. 235-248.

8. Rebelo I, Carvalho-Guerra F, Pereira-Leite L, Quintanilha A. Comparative study of lactoferrin and other blood markers of inflammatory stress between preeclamptic and normal pregnancies. Eur J Obstet Gynecol Reprod Biol 1996; 64:167-73.

9. Luthy D, Williams M, Zhang C, Walsh S, Walsh D, Sorensen T. Elevated first trimester serum Creactive protein and subsequent risk of preeclampsia. Am J Obstet Gynecol 2001; 184:S77.

10.National High Blood Pressure Education Program Working Group on High Blood Pressure in Pregnancy. Report of the National Blood Pressure Education Program Working Group on High Blood Pressure in Pregnancy. Am J Obstet Gynecol 2000; 183:S1-S22.

11.Ness RB, Roberts JM. Heterogeneous causes constituting the single syndrome of preeclampsia: a hypothesis and its implications. Am J Obstet Gynecol 1996; 175:1365-70.

12.VanWijk MJ, Kublickiene K, Boer K, VanBavel E. Vascular function in preeclampsia. Cardiovasc Res 2000; 47:38-48.

13. Hauth J, Sibai B, Caritis S, et al. Maternal serum thromboxane B2 concentrations do not predict improved outcomes in high-risk pregnancies in a low-dose aspirin trial. Am J Obstet Gynecol 1998; 179:1193-9.

\section{ERRATA}

Associação entre a Incisura Diastólica das Artérias Uterinas e a

Histologia do Leito Placentário em Grávidas

com Pré-eclâmpsia

RBG0 no 07 - vol 23 - 2001, página 435

TABELAS: 2,3 e 5

TESTE EXATO DE FISHER $p<0,05$ em vez de $p=0,05$ 